\title{
HIGH PRESSURE CRYSTALLIZATION OF III-V NITRIDES
}

\author{
S. POROWSKI \\ High Pressure Research Center, Polish Academy of Sciences \\ Sokołowska 29/37, 01-142 Warszawa, Poland
}

\begin{abstract}
Crystal growth from the solution under high $\mathrm{N}_{2}$ pressure (HNP method) results in high quality $\mathrm{mm}$ size crystals of $\mathrm{GaN}$ in 5 to 24 hour process. The crystallization of AlN is less efficient due to relatively lower solubility of nitrogen in the liquid Al. Possibility of InN growth is strongly limited since this compound is unstable at $T>600^{\circ} \mathrm{C}$ even at $20 \mathrm{kbar}$. The growth of $\mathrm{cm}$ size high quality $\mathrm{GaN}$ crystals requires lower supersaturations and longer processes.
\end{abstract}

PACS numbers: $81.10 .-\mathrm{h}$

\section{Introduction}

Currently, the layers of III-V nitrides are grown on foreign substrates, mainly sapphire. Due to very high melting temperatures and/or pressures at melting, the substrate crystals of considered nitrides cannot be obtained by typical methods like Czochralski or Bridgman growth from the stoichiometric melts. Therefore, lower temperature methods, i.e. growth from the solution, have to be applied.

\section{Thermal stability}

The melting temperatures, $T^{\mathrm{M}}$, and corresponding equilibrium pressures at melting, of III-N compounds were not measured. The melting temperatures were calculated by the use of Van Vechten's quantum dielectric theory of chemical bonding [1]. In Table I we have shown the calculated values of $T^{\mathrm{M}}$ and the estimations for corresponding pressures.

$\mathrm{AlN}, \mathrm{GaN}$ and InN are tetrahedrally coordinated, strongly bonded compounds. The bonding energies are 2.88, 2.24 and $1.93 \mathrm{eV}$ [5] for AlN, GaN and InN, respectively, whereas for i.e. GaAs it is $1.63 \mathrm{eV}$. The consequence of this are high melting temperatures, but also, good thermal stability of AIN and GaN. At $\mathrm{N}_{2}$ pressure of $1 \mathrm{bar}, \mathrm{AlN}, \mathrm{GaN}$ and $\mathrm{InN}$ are thermodynamically stable up to 2563 [6], 854 [7] and $\approx 400^{\circ} \mathrm{C}$ [2] respectively. On the other hand, these temperatures are quite far from the expected melting points. Due to the strong triple bond 
TABLE I

Melting conditions for AlN, GaN and InN.

\begin{tabular}{l|c|c|c|c|c}
\hline \hline Nitride & $T^{\mathrm{M}}[\mathrm{K}]$ & Ref. & $p_{\mathrm{N}_{2}}^{*}[\mathrm{kbar}]$ & $p_{\mathrm{N}_{2} \exp }^{* *}[\mathrm{kbar}]$ & Ref. \\
\hline AlN & 3487 & {$[1]$} & 0.2 & $>0.1$ & {$[3]$} \\
$\mathrm{GaN}$ & 2791 & {$[1]$} & 45 & $>30$ & {$[4]$} \\
InN & 2146 & {$[2]$} & 60 & $>35$ & {$[2]$} \\
\hline
\end{tabular}

* Extrapolation of the experimental equilibrium data.

** The highest pressure at which the decomposition has been observed.

in $\mathrm{N}_{2}$ molecule $(9.76 \mathrm{eV})$, the pressure over $\mathrm{InN}$ and $\mathrm{GaN}$ reaches very high values, of several tenths of kbar, at temperatures approaching the melting points. For AlN, where nitrogen is bonded in the crystal very strongly, the pressure is not so high, however, at $2800^{\circ} \mathrm{C}$, the decomposition pressure is higher than 100 bar [3]. In Fig. 1 we have shown the equilibrium curves for considered compounds.

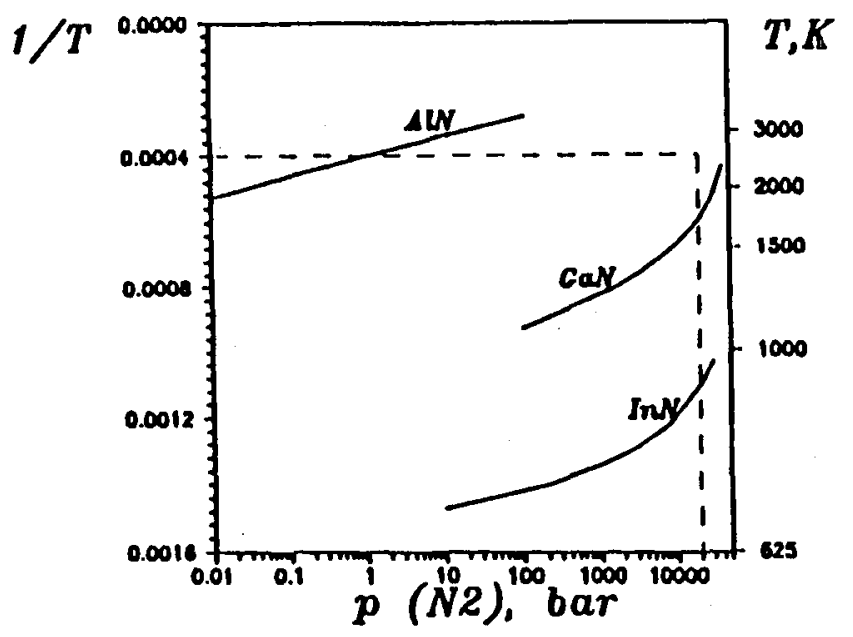

Fig. 1. Equilibrium $\mathrm{N}_{2}$ pressure over III-V nitrides: $\mathrm{AlN}$ [6], GaN [4], InN [2].

The equilibrium $p-T$ curves for InN and GaN deviate from linear dependence due to nonideality of $\mathrm{N}_{2}$, accordingly, and the pressure is lowered in relation to that predicted for an ideal gas.

For our experimental system, where $20 \mathrm{kbar}$ and $1800^{\circ} \mathrm{C}$ in reasonable volume (1-5 $\left.\mathrm{cm}^{3}\right)$ is possible, each of the nitrides has its own experimental limitations.

For AlN, we have only the technical limit related to temperature since the pressure requirements can be assured even for melting.

For InN, we have the pressure limit of $20 \mathrm{kbar}$ which determines the maximum temperature of InN stability. This is only $550-570^{\circ} \mathrm{C}$ which is very far from the expected melting point. 
For GaN, the maximum equilibrium temperature determined by pressure of $20 \mathrm{kbar}$ is $1600^{\circ} \mathrm{C}$ which is the closest to melting. This creates the best conditions for crystallization among the considered nitrides.

\section{Liquidus curves}

In Fig. 2 we have shown the experimental data of nitrogen solubility in liquid gallium [8]. At the temperature range of $1200-1600^{\circ} \mathrm{C}$, the equilibrium content of $\mathrm{N}$ in the liquid increases by two orders of magnitude and reaches $10^{-2}$ at. fraction.

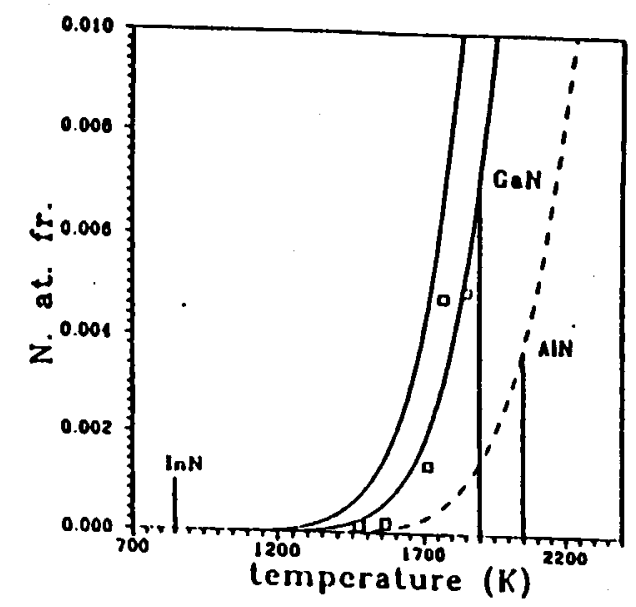

Fig. 2. Solubility of $\mathrm{N}$ in liquid $\mathrm{Al}, \mathrm{Ga}, \mathrm{In}$.

The solubility curves for AlN, GaN and InN calculated in regular solution approximation are shown in Fig. 2. The data indicate that at the conditions available in gas pressure system, the highest solubility can be expected for GaN and the lowest for InN.

\section{Synthesis and crystal growth}

\subsection{Experimental}

Crystal growth experiments were performed in a gas pressure chambers of internal diameter $30 \mathrm{~mm}$ (the growth setup was presented in Ref. [9]) with a furnace of inside diameter $14 \mathrm{~mm}\left(1500^{\circ} \mathrm{C}\right)$ or $10 \mathrm{~mm}\left(1800^{\circ} \mathrm{C}\right)$ and with a $\mathrm{BN}$ crucible containing Al, Ga or In. The temperatures were stabilized with the precision better than $1^{\circ}$. Usually, the crystals were grown at a pressure for which the nitride was stable over the whole temperature range along the crucible.

\subsection{Results - AlN and InN}

At high $\mathrm{N}_{2}$ pressure, the synthesis rate is very high for AlN and extremely low for InN. The rate of AlN synthesis is so high that, at pressure lower than $6.5 \mathrm{kbar}$, thermal explosion is observed during heating of the bulk $\mathrm{Al}$ sample (Fig. 3). 


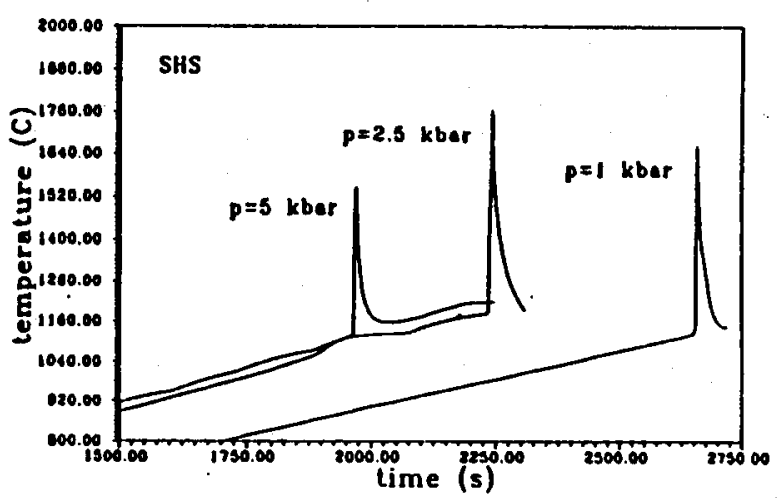

Fig. 3. Temperature of the Al sample during heating at a rate of $20 \% \mathrm{~min}$, at high $\mathrm{N}_{2}$ pressure.

The combustion product is AlN powder or ceramics. At higher pressures, a tight AlN layer inhibits further reaction and the metal can be heated up to the temperature of crystallization.

Due to low solubility, the crystallization rate of $\mathrm{AlN}$, at $1600-1800^{\circ} \mathrm{C}$, is rather low $(<0.02 \mathrm{~mm} / \mathrm{h})$.

Due to kinetic (low temperature) and thermodynamical (low solubility) barriers crystal growth experiments for InN resulted in very small crystallites (5-50 $\mu \mathrm{m}$ ), grown by slow cooling of the system from the temperatures exceeding the stability limit for InN.

\subsection{Results - GaN}

GaN crystals were grown from the solution in liquid $\mathrm{Ga}$, in quasilinear temperature gradient of $30-100^{\circ} / \mathrm{cm}$, in 5-24 hour processes. The experiments were performed at $\mathrm{N}_{2}$ pressure of 8-17 kbar, at temperatures of $1300-1600^{\circ} \mathrm{C}$.

A typical synthesis solid diffusion (SSD) crystallization mechanism was observed. The synthesis of thin polycrystalline GaN film on the Ga surface, its dissolution and transport into the cooler part of the crucible lead to the nucleation and growth of GaN single crystals.

The morphology of the crystals depends on pressure, temperature range and supersaturation during growth. For pressures and temperatures lying deep in the GaN stability field (higher pressures, lower temperatures), the crystals are hexagonal prisms elongated in the $c$-direction. At the conditions close to the equilibrium curve, the dominating shape is a hexagonal plate.

The crystals which grow slowly (slower than $0.1 \mathrm{~mm} / \mathrm{h}$ ), i.e. at smaller temperature gradients, are of high structural quality. They are transparent, slightly yellowish, and have flat mirror-like surfaces. In Fig. 4a we have shown some of these crystals grown at $1400-1500^{\circ} \mathrm{C}$, at $10 \mathrm{kbar}$ in a $20 \mathrm{~h}$ process. Figure $4 \mathrm{~b}$ is one of the scanning tunneling microscopy (STM) scans [13] of (0001) surface. STM measurements confirm that the surfaces of the crystals are flat, however, some steps $20-40 \AA$ high were observed. 


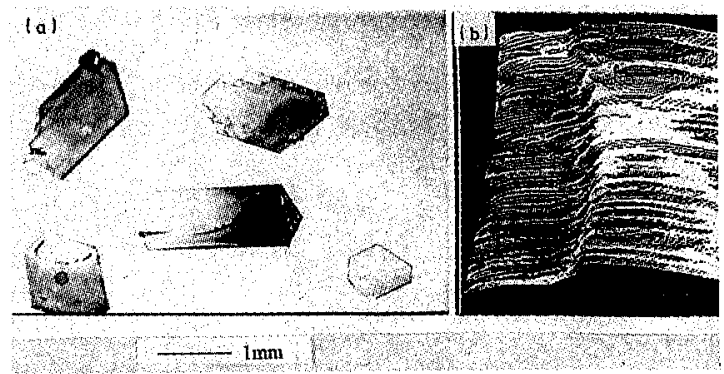

Fig. 4. (a) GaN single crystals grown at $10 \mathrm{kbar}$ in $10 \mathrm{~h}$, (b) STM scan indicating $40 \AA$ step on $\mathrm{GaN}$ (0001) surface.

Typical widths (FWHM) of X-ray rocking curves for (004) Cu $K_{\alpha}$ reflection, are 23-32 arcsec. The FWHM determined in several points (typically 8 ) for the GaN platelets $2.5 \times 2.5 \mathrm{~mm}$ scatters by \pm 3 arcsec. The typical X-ray rocking curve for (0004) reflection, characterizing the crystals, is shown in Fig. 5a. The curve is significantly narrower than the curves of heteroepitaxial GaN layers grown by MOCVD (metalorganic chemical vapor deposition) or MBE (molecular beam epitaxy). This is illustrated in Fig. 5b.
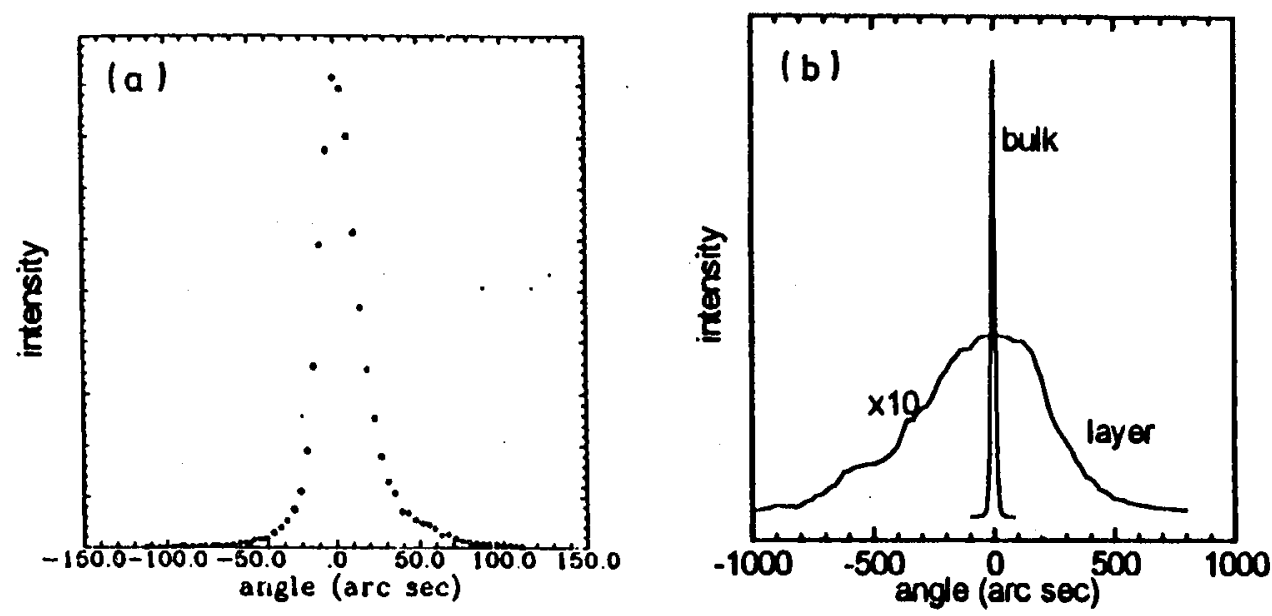

Fig. 5. (a) Rocking curve for GaN plate. (b) Rocking curves for crystal and heteroepitaxial layer grown by MOCVD on sapphire substrate [14].

A GaN $2 \mathrm{~mm}$ plate was used as a substrate for $\mathrm{GaN}$ homoepitaxial growth by HNP Ga vapor transport, in temperature gradient. A $5 \mu \mathrm{m} \mathrm{GaN} \mathrm{layer} \mathrm{was}$ obtained in $3 \mathrm{~h}$ process. The rocking curve of the layer was broadened, in relation to the substrate, up to $40-42$ arcsec.

The quality of GaN crystals deteriorates with increasing growth rate (high supersaturations) and with dimension of the crystals. The latter is related to the 

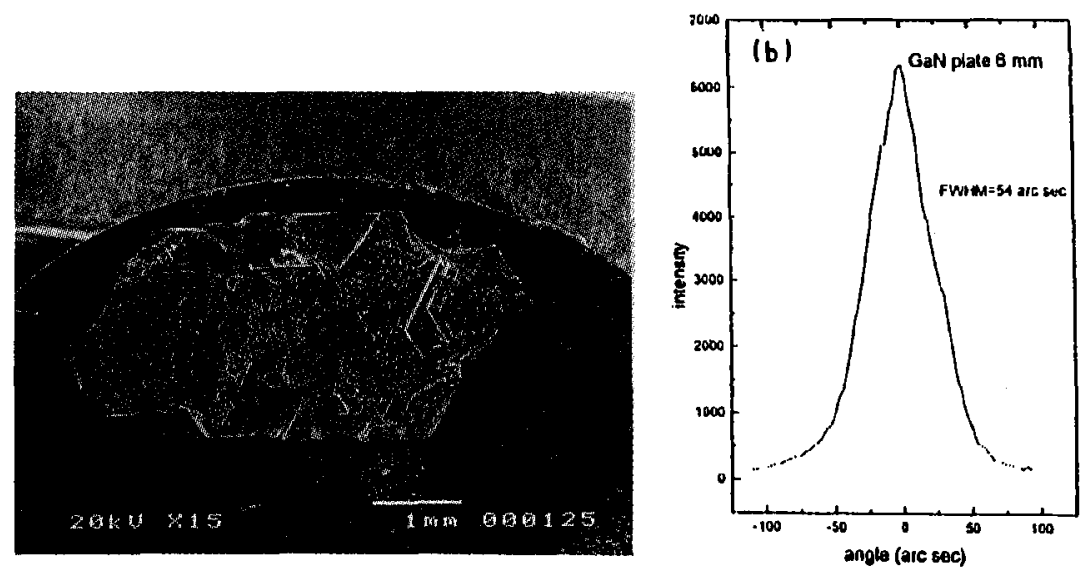

Fig. 6. (a) $\mathrm{GaN}$ plate grown at $1250-1400^{\circ} \mathrm{C}$, at $12 \mathrm{kbar} \mathrm{N}_{2}$ pressure during $8 \mathrm{~h}$. (b) Rocking curve of the crystal from Fig. 6 a measured with $1 \times 3 \mathrm{~mm}$ X-ray beam.

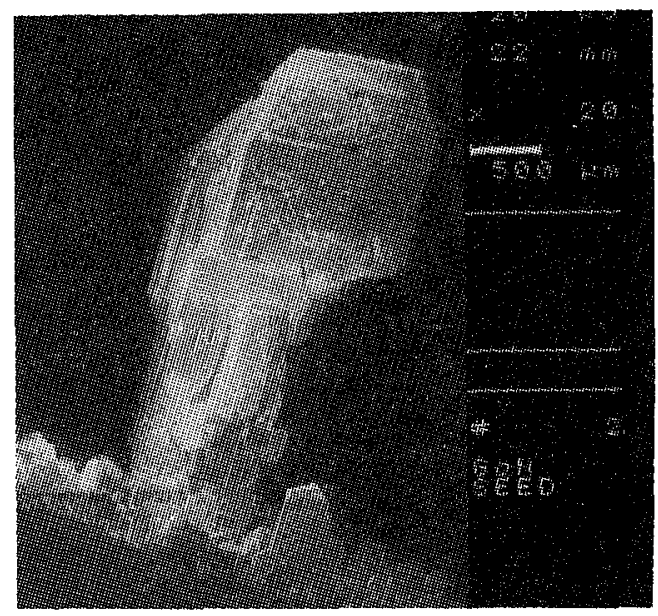

Fig. 7. Growth of GaN on GaN seed crystal.

non-uniform distribution of nitrogen in the solution across the growing crystal face, especially if the face reaches the size comparable with size of the crucible. In this case the layer-by-layer growth mechanism is strongly disturbed. This leads to the formation of macrosteps on the crystal surfaces and acceleration of the growth near the edges of the crystals. In extreme, for the growth rates above $1 \mathrm{~mm} / \mathrm{h}$, the formation of unstable: hollow, skeletal or dendritic crystals is observed.

The deterioration of quality of the 5-10 mm crystals grown at the rate of $0.5-1 \mathrm{~mm} / \mathrm{h}$ is reflected in the broadening of the rocking curve. Figure 6 shows $6 \mathrm{~mm} \mathrm{GaN} \mathrm{plate} \mathrm{and} \mathrm{its} \mathrm{rocking} \mathrm{curve.} \mathrm{The} \mathrm{FWHM} \mathrm{of} \mathrm{the} \mathrm{curve} \mathrm{is} 50$ arcsec. In some cases, the splitting of the reflection curve into two or three peaks is observed 
TABLE II

Physical properties of $\mathrm{GaN}$ crystals grown under high $\mathrm{N}_{2}$ pressure.

\begin{tabular}{|c|c|c|}
\hline Property & Value & Method \\
\hline Lattice constants & $\begin{array}{l}a=3.1879-3.1895 \pm 0.0004 \AA \\
c=5.1856-5.1863 \pm 0.0002 \AA\end{array}$ & Bond \\
\hline Size & up to $2.5 \times 2.5 \times 0.2 \mathrm{~mm}$ & \\
\hline Rocking curve (0004), $\mathrm{Cu} K_{\alpha}$ & $23-32$ arcsec & \\
\hline Surface $(0001)$, as grown & $\begin{array}{l}\text { flat } \\
\text { steps } 20-40 \AA\end{array}$ & $\begin{array}{l}\text { SEM } \\
\text { STM }\end{array}$ \\
\hline Impurity content & $<0.1 \%$ & EDX \\
\hline Electron concentration & $\approx 10^{19} \mathrm{~cm}^{-3}$ & optical, Hall effect \\
\hline Mobility & $\approx 100 \mathrm{~cm}^{2} /(\mathrm{V} \mathrm{s})$ & el. conductivity \\
\hline$E_{\mathrm{g}}+E_{\mathrm{F}}$, at $20 \mathrm{~K}$ & $3.55-3.58 \mathrm{eV}$ & optical absorption \\
\hline Pressure coeff. of $E_{\mathrm{g}}$ & $4.7 \mathrm{meV} / \mathrm{kbar}$ & opt. abs. in DAC \\
\hline Refractive index at $1.7 \mathrm{eV}$ & 2.43 & \\
\hline $\begin{array}{l}\text { Photoluminescence on } \mathrm{Zn} \\
\text { at room temp. }\end{array}$ & $2.85 \mathrm{eV}$ & \\
\hline Bulk modulus & $2450 \mathrm{kbar}$ & EXAFS \\
\hline Thermal expansion coeff. & $\begin{array}{l}\alpha_{a(294 \mathrm{~K})}=3.1 \times 10^{-6} \mathrm{~K}^{-1} \\
\alpha_{c(294 \mathrm{~K})}=2.8 \times 10^{-6} \mathrm{~K}^{-1} \\
\alpha_{a(700 \mathrm{~K})}=6.2 \times 10^{-6} \mathrm{~K}^{-1} \\
\alpha_{c(700 \mathrm{~K})}=6.1 \times 10^{-6} \mathrm{~K}^{-1}\end{array}$ & X-ray \\
\hline Phonon energies & $\begin{array}{l}A_{1}(\mathrm{TO})=530 \mathrm{~cm}^{-1} \\
E_{1}(\mathrm{TO})=560 \mathrm{~cm}^{-1} \\
E_{2}(\text { high })=568 \mathrm{~cm}^{-1} \\
E_{2}(\text { low })=144 \mathrm{~cm}^{-1}\end{array}$ & Raman scattering \\
\hline GaN plate & & \\
\hline Size & $5-10 \mathrm{~mm}$ & \\
\hline Rocking curve & $48-54 \operatorname{arcsec}$ & \\
\hline $\begin{array}{l}\text { Surface }(0001) \text { as grown } \\
\text { Homoepitaxial layer on } \mathrm{GaN} \\
\quad 2 \times 2 \mathrm{~mm} \text { substrate }\end{array}$ & macrosteps $1-3 \mu \mathrm{m}$ & SEM, STM \\
\hline Rocking curve & & \\
\hline substrate & $25-30 \operatorname{arcsec}$ & \\
\hline layer & $38-42$ arcsec & \\
\hline
\end{tabular}

which indicates the presence of low angle (1-2 arcmin) boundaries in the cm size GaN crystals.

Attempts to grow $\mathrm{GaN}$ on single crystalline GaN seed were also undertaken. Figure 7 shows a GaN crystal grown on $0.4 \times 1.6 \mathrm{~mm}$ needle shaped GaN seed, in 
vertical crucible, in $8 \mathrm{~h}$ process. The use of seed hindered the growth of GaN crystals on the crucible walls. Layer growth on the seed faces was observed, however, patterns characteristic of unstable growth (edge nucleation, accelerated growth near edges and macrosteps) were also visible.

Physical properties of the crystals were determined by X-ray [10], electrical and optical [11] measurements. Pressure dependences of energy gap [11] and phonon energies [12] were measured. Table II contains the fundamental physical properties of pressure grown GaN crystals.

\section{Conclusions}

High quality crystals of III-N compounds can be grown at nitrogen pressure up to $20 \mathrm{kbar}$. At this pressure range, the best results were obtained for GaN. AlN requires higher temperatures to increase the solubility of $\mathrm{N}$ in the liquid Al. For InN, the pressure of $20 \mathrm{kbar}$ is not sufficient for effective crystallization.

\section{References}

[1] J.A. Van Vechten, Phys. Rev. B 7, 1479 (1973).

[2] I. Grzegory, S. Krukowski, J. Jun, M. Bockowski, M. Wroblewski, S. Porowski, in: Proc. XX AIRAPT Conference, Colorado Springs 1993.

[3] W. Class, Contract Rep., NASA-Cr-1171, 1968.

[4] J. Karpinski, J. Jun, S. Porowski, J. Cryst. Growth 66, 1 (1984).

[5] W.A. Harrison, Electronic Structure and Properties of Solids, Freeman, San Francisco 1980.

[6] G.A. Slack, T.F. Mac Nelly, J. Cryst. Growth 34, 276 (1976).

[7] J. Karpinski, S. Porowski, J. Cryst. Growth 66, 11 (1984).

[8] I. Grzegory, M. Bockowski, J. Jun, P. Figurny, High Press. Res. 7/8, 284 (1991).

[9] S. Porowski, I. Grzegory, J. Jun, in: High Pressure Chemical Synthesis, Eds. J. Jurczak, B. Baranowski, Elsevier, Amsterdam 1989, p. 21.

[10] M. Leszczynski, I. Grzegory, M. Bockowski, J. Cryst. Growth 126, 601 (1993).

[11] P. Perlin, I. Gorczyca, N.E. Christensen, I. Grzegory, H. Teisseyre, T. Suski, Phys. Rev. B 45, 13307 (1992a).

[12] P. Perlin, C. Jauberthie-Carillon, J.P. Itie, A. San Miguel, I. Grzegory, A. Polian, Phys. Rev. B 45, 83 (1992b).

[13] A. Witek, to be published.

[14] M. Leszczynski, P. Perlin, T. Suski, H. Teisseyre, I. Grzegory, S. Porowski, J. Jun, to be published in Appl. Phys. Lett. 